and working periods. The PEF assessment graphic and job history were interpreted as; compatible with OA, compatible with WEA and technically not approved.

Result Two hundred and fourteen patients admitted to our clinic with WRA suspicion between November 2013 and June 2016. They were referred by an occupational health specialist, personal application, second- or third-line chest disease specialists [61 (28\%), 51 (23\%), and 102 (47\%) respectively]. Fiftyfour patients $(25 \%)$ were diagnosed with occupational asthma (OA), and $24(11 \%)$ with work exacerbated asthma (WEA), total 78 workers diagnosed with WRA. Twenty five $(32,1 \%)$ had allergic rhinitis. The most commonly used test were PEF monitoring and BPT respectively.

Discussion PEF monitoring, non-specific BPT and skin prick test for suitable cases would be sufficient besides occupational history and clinical properties for the diagnosis of WRA. PEF assessment, one of the most important tests for the diagnosis of WRA, must be performed.

\section{ACUTE IRRITANT-INDUCED ASTHMA CAUSED BY OZONE}

${ }^{1}$ Karl Færden*, ${ }^{1}$ Britt Grethe Randem, ${ }^{2}$ Per Arve Lier, ${ }^{3}$ Bjørn Granhus, 'Per Søstrand, 4,5Johny Kongerud. 'Department of Environmental and Occupational Medicine, Os/o University Hospital, Oslo, Norway; ${ }^{2}$ Humana Sandvika AS, Sandvika, Norway; ${ }^{3}$ Oslo Police District, Occupational Health Service, Oslo, Norway; ${ }^{4}$ Department of Respiratory Medicine, Rikshospitalet, Oslo University Hospital, Oslo, Norway; ${ }^{5}$ Faculty of Medicine, University of Oslo, Oslo, Norway

\subsection{6/oemed-2018-ICOHabstracts.1265}

Introduction Ozone-generating UV-lamps are used to remove unwanted grease from ventilation systems.

Irritant asthma after exposure to artificially produced ozone has been described at a Norwegian fish hatchery and a sewage plant, as well as in the Swedish paper industry.

We present cases that developed asthma after an accident with ozone-producing UV-systems in a restaurant kitchen.

Methods Case series Seven subjects that developed asthma were studied in relation to exposure, symptoms, medical history and clinical findings including lung function measurements, reversibility of airflow limitation and bronchial hyper responsiveness (BHR) to methacholine, both shortly after the accidental exposure and two years after the incident.

Result Out of a total number of 127 possibly ozone-exposed employees, 55 employees reported symptoms, and seven employees were diagnosed with occupational asthma after the incident. Six of these seven subjects had either positive reversibility and/or positive BHR tests.

Two years after cessation of exposure all seven subjects still needed treatment for asthma.

Three of the subjects had BHR despite the use of inhaled corticosteroids, all graded as 'very mild BHR'. FVC, FEV1, FEV1/FVC ratio and FeNO values were within normal range in all cases. None had long absence from work or needed emergency treatment in hospital for their asthma.

Discussion The adverse impact of ozone exposure on the airways is well known from epidemiological studies, where the focus has been on the negative health effects of ozone $\left(\mathrm{O}_{3}\right)$ in ambient air, especially in large cities. Commercial use of the ozone gas' odour absorbing and germ-killing properties has become more common in the last decade.

Accidents involving ozone gas from air purifiers with UVlamps may cause acute irritant asthma. There is a need for greater awareness in the use of ozone-generating devices.

\section{ASTHMA CONTROL AND WORK DISABILITY IN SUBJECTS PREVIOUSLY EVALUATED FOR WORK- RELATED ASTHMA WITH SPECIFIC INHALATION CHALLENGE}

Ilenia Folletti*, Umberto Giovannelli, Giulia Paolocci, Marco dell'Omo, Angela Gambelunghe, Nicola Murgia, Giacomo Muzi. Section of Occupational Medicine, Respiratory Diseases and Toxicology, University Of Perugia, Perugia, Italy

\subsection{6/oemed-2018-ICOHabstracts. 1266}

Background Currently available studies show that removal of subjects affected by occupational asthma from exposure does not always lead to an improvement in respiratory function. The cause of this is still unclear. The aim of our study was to evaluate in 2017 lung function and severity of asthma in subjects who underwent specific inhalation challenge (SIC) between 2006 and 2015 for work-related asthma.

Methods Clinical charts of 35 workers who underwent SIC have been evaluated. They were interviewed by telephone using a questionnaire to asses demographic data, respiratory symptoms and work disability. The severity of asthma was evaluated according to the GINA guidelines and asthma control was assessed by Asthma Control Questionnaire (ACQ). 18 workers agreed also to perform also spirometry.

Results 10 subjects had a positive SIC and 25 a negative SIC. Subjects with positive SIC had more frequently moderate persistent asthma treated with a combination of inhaler steroids and a bronchodilator (67\%) and those with negative SIC had more frequently intermittent asthma $(65 \%)$ treated with salbutamol as needed $(\mathrm{p}<0.05)$. The score of ACQ was greater among subjects with positive SIC than with negative SIC (11 vs $4, \mathrm{p}<0.05)$. Spirometry on 18 subjects showed among those with positive SIC a FEV1 lower (- 6\% in mean) and a RV greater $(+15 \%)$ compared to those with negative SIC. Subjects with positive SIC had more economic loss than subjects with negative SIC $(\mathrm{p}<0.05)$.

Conclusions Subjects who have had a positive SIC showed more severe asthmatic symptoms with lower asthma control despite current pharmacological therapy. They also had a higher RV than subjects with negative SIC. This could be a relevant parameter to evaluate in subjects with occupational asthma to improve asthma control.

\section{OCCUPATIONAL ASTHMA DUE TO EXPOSURE TO RHESUS MONKEY}

1,2S Keirsbilck*, 1,2E Adams, 1,3E Vandebroek, 'S Ronsmans, 1,4B Nemery. 'Clinic for occupational and environmental medicine, University Hospital Gasthuisberg, Leuven, Belgium; ${ }^{2}$ IDEWE, External Service for Prevention and Protection at Work, Heverlee, Belgium; ${ }^{3}$ Premed, External Service for Prevention and Protection at Work, Leuven, Belgium; ${ }^{4}$ Environment and Health, Department of Public Health and Primary Care, K.U.Leuven, Leuven, Belgium

\subsection{6/oemed-2018-ICOHabstracts. 1267}

Introduction A common cause of occupational asthma is exposure to animal proteins. Knowing this, laboratory workers are at risk when they work with laboratory animals (e.g. mice, rats, guinea pigs, rabbits). No reports were made up to date of allergy to rhesus monkey.

Methods We used all available information of the medical file of the patient. The patient explicitly authorised us to publish her case. 